Research paper

\title{
First report of the effect of Ocotea elegans essential oil on Rhipicephalus (Boophilus) microplus
} \author{
Leandro Rocha ${ }^{\mathrm{b}, \mathrm{e}}$, Ana Carolina S. Chagas ${ }^{\mathrm{f}}$ \\ a Universidade Estadual Paulista “Júlio de Mesquita Filho" (UNESP), Jaboticabal, São Paulo, Brazil \\ ${ }^{\mathrm{b}}$ Universidade Federal do Rio de Janeiro (UFRJ), Rio de Janeiro, Rio de Janeiro, Brazil \\ ${ }^{\mathrm{c}}$ Centro Universitário Central Paulista (UNICEP), São Carlos, São Paulo, Brazil \\ ${ }^{\mathrm{d}}$ Universidade do Estado do Rio de Janeiro (UERJ), São Gonçalo, Rio de Janeiro, Brazil \\ e Universidade Federal Fluminense (UFF), Niterói, Rio de Janeiro, Brazil \\ ${ }^{\mathrm{f}}$ Embrapa Pecuária Sudeste (CPPSE), São Carlos, São Paulo, Brazil
}

Amanda Figueiredo ${ }^{\mathrm{a}, *}$, Leonor M. Nascimento ${ }^{\mathrm{b}}$, Louyse G. Lopes ${ }^{\mathrm{c}}$, Rodrigo Giglioti ${ }^{\mathrm{a}}$, Ricardo D.D.G. Albuquerque $^{\mathrm{b}}$, Marcelo G. Santos ${ }^{\mathrm{d}}$, Deborah Q. Falcão ${ }^{\mathrm{e}}$, Jeane A.P. Nogueira ${ }^{\mathrm{b}}$,

\section{A R T I C L E I N F O}

\section{Keywords:}

Cattle tick

Resistance

Alternative control

Repellency

Sesquirosefuran

\begin{abstract}
A B S T R A C T
Rhipicephalus (Boophilus) microplus is responsible for reducing animal welfare, causing a drop in productive performance and transmitting hemoparasites. The main strategy of tick control is application of synthetic acaricides. However, parasite resistance to these compounds is a major concern. Therefore, the acaricidal and repellent in vitro effect of the Ocotea elegans essential oil on larvae and adult females of $R$. (B.) microplus were evaluated. The larval packet test (LPT), larval repellency test (RT) and adult immersion test (AIT) were performed. The essential oil was analyzed by gas chromatography (GC/FID) and the structure of the oil's major constituent (92.2\% sesquirosefuran) was elucidated by nuclear magnetic resonance. In the AIT, efficacy higher than $90 \%$ was detected from the concentration $25 \mathrm{mg} / \mathrm{mL}$ upward. In both LPTs performed after $48 \mathrm{~h}$, only the $100 \mathrm{mg} / \mathrm{mL}$ concentration resulted in mortalities above $70 \%$. On the other hand, the essential oil caused an average of $95.8 \%$ repellency from 0.78 to $100 \mathrm{mg} / \mathrm{mL}$. The $\mathrm{LC}_{50}$ in the two LPT $(48 \mathrm{~h})$ tests were 59.68 and $25.59 \mathrm{mg} / \mathrm{mL}$, respectively. The $\mathrm{LC}_{50}$ and $\mathrm{LC}_{90}$ in the AIT were 4.96 and $17.37 \mathrm{mg} / \mathrm{mL}$, and in the RT they were 0.04 and $1.24 \mathrm{mg} / \mathrm{mL}$ respectively. We conclude that the essential oil of $O$. elegans leaves has a significant acaricidal effect on engorged females and on larval repellency of $R$. (B.) microplus ticks, and can be a promising alternative for the control of this ectoparasite.
\end{abstract}

\section{Introduction}

The importance of the tick Rhipicephalus (Boophilus) microplus (Canestrini, 1887) is strongly related to the damages caused by its parasitism, since it directly affects animal welfare, resulting in stress, anemia due to blood spoliation, reduction of productive and reproductive performance, and transmits hemoparasites (causing bovine babesiosis and anaplasmosis). This complex of diseases can cause high mortality rate in herds. So, the economic impact is huge in both dairy and beef sectors. In Brazil, losses due to the cattle tick are estimated at US\$ 3.24 billion per year from reduced productivity and costs for treatment (Grisi et al., 2014; Raynal et al., 2013; Rodrigues and Leite, 2013).

The application of chemical acaricides has become indispensable for cattle production and is the main method used for tick control (Cruz et al., 2015; Furtado et al., 2013). However, scientific reports of resistance of $R$. (B.) microplus to the chemical acaricides available in the market are alarming (Higa et al., 2016; Klafke et al., 2017; Raynal et al., 2013). In the search for new drugs, substances of plant origin have demonstrated high efficacy in vitro and can be associated with commercial products to prolong the efficacy by reducing the selective pressure for development of resistant tick strains (Chagas, 2015; Roel, 2001). Active molecules from plant species have interesting characteristics for parasite control in animal production systems, such as reduced environmental impact, reduced residues in food, lower cost and delayed parasite resistance (Mello-Peixoto et al., 2013; Roel, 2001).

Ocotea elegans Mez belongs to the Lauraceae, a botanical family with a pantropical distribution. Many Lauraceae species are economically important for containing several substances with use in the pharmaceutical, chemical, food and cosmetic industries, as well as in

\footnotetext{
* Corresponding author.

E-mail address: amanda.figueiredo@colaborador.embrapa.br (A. Figueiredo).
} 
construction, carpentry and papermaking (Marques et al., 2004; Rohwer, 1993). The genus Ocotea has about 350 species, found throughout tropical and subtropical America, Madagascar, Africa and the Canary Islands (Quinet, 2005). Ocotea elegans Mez, popularly known as "canela-sassafrás" in Brazil, occurs in the southeastern and southern Brazilian Atlantic Forest and in Paraguay (Kropf et al., 2015).

Several classes of compounds have been isolated from the genus Ocotea, such as terpenoids, alkaloids, neolignans, allyl phenols, coumarins, and sesquiterpenlactones (Hess, 1995). Recent in vitro studies have detected acaricidal effect of Ocotea lancifolia and Ocotea diospyrifolia etanolic extracts on $R$. (B.) microplus engorged females and larvae (Barbosa et al. 2013; Santos et al., 2013). Likewise, Conceição et al. (2017) evaluated hexane, ethyl acetate and ethanol extracts of Ocotea acidophyla leaves and all of them demonstrated acaricidal activity against different stages of the cattle tick. Several species of the Lauraceae family occurring in Brazil have not yet been investigated for their possible biological activities (Marques, 2001; Yamaguchi et al., 2012). Based on this and taking into account the activities of the Ocotea genus reported in the literature, the present study aimed to evaluate in vitro the acaricidal and repellent effect of $O$. elegans essential oil on $R$. (B.) microplus larvae and adult females.

\section{Material and methods}

\subsection{Collection of plant material and extraction of Ocotea elegans essential} oil

O. elegans leaves were collected from different specimens in Restinga de Jurubatiba National Park (PNRJ), in the municipality of Carapebus, Rio de Janeiro state, Brazil ( $22^{\circ} 18^{\prime} 32^{\prime \prime}$, and $41^{\circ} 66^{\prime} 11^{\prime \prime} \mathrm{W}$ ), during the day, in November and December 2014 and January 2015, under authorization of the federal environmental agency IBAMA (permit 13659-2) The identification of the species was carried out by Dr. Marcelo Guerra Santos and a voucher specimen was deposited at the herbarium of the Teacher Training School of Rio de Janeiro State University, under registration number RFFP 16.873. The material was placed in a $5 \mathrm{~L}$ round-bottom flask and brought to boil to allow hydrodistillation for $4 \mathrm{~h}$ in a Clevenger-type apparatus. The oil was collected and stored at $4{ }^{\circ} \mathrm{C}$ for further analyses. This procedure was previously described by Tietbohl et al. (2014).

\subsection{Chemical analysis of the essential oil}

The essential oil was analyzed by a GCMS-QP5000 (Shimadzu) gas chromatograph, equipped with a mass spectrometer using electron ionization (GC/MS). One microliter of essential oil, dissolved in n-hexane $(1: 100 \mathrm{mg} / \mu \mathrm{L})$, was injected into a RTX-5 column $(30 \mathrm{~m} \times 0.32 \mathrm{~mm} \times 0.25 \mu \mathrm{m})$. The GC conditions were as follows: injector temperature, $260^{\circ} \mathrm{C}$; detector temperature, $290^{\circ} \mathrm{C}$; carrier gas (Helium), flow rate $1 \mathrm{~mL} / \mathrm{min}$. and split injection with 1:40 split ratio. Oven temperature was initially $60^{\circ} \mathrm{C}$ and then raised to $290^{\circ} \mathrm{C}$ at a rate of $3{ }^{\circ} \mathrm{C} / \mathrm{min}$. The mass spectrometry conditions were voltage of $70 \mathrm{eV}$ and scan rate of $1 \mathrm{scan} / \mathrm{s}$. The retention indices were calculated by interpolating the retention times of a mixture of aliphatic hydrocarbons (C9-C30) analyzed under the same conditions. Identification of the substances was performed by comparing their retention indices and mass spectra with those reported in the literature (Adams, 2007). The mass fragmentation pattern was also checked with the NIST (National Institute of Standards and Technology) mass spectra libraries. Quantitative analysis of the chemical constituents was performed by flame ionization gas chromatography (GC/FID), under the same conditions as GC/MS analysis, and percentages were obtained by the FID peak-area normalization method.

The identification and structural elucidation of the main essential oil substance was performed by nuclear magnetic resonance (NMR). The spectra of ${ }^{1} \mathrm{H}$ NMR and ${ }^{13} \mathrm{C}$ NMR were obtained in a Varian VNMRS spectrometer with frequencies of 300 and $500 \mathrm{MHz}^{1} \mathrm{H}$ and $125 \mathrm{MHz}$ for ${ }^{13} \mathrm{C}$, using deuterated solvent and TMS as internal standard. Chemical shifts $(\delta)$ were expressed in parts per million (ppm). Spectral editing was performed using SpinWorks 3.1.5.0 and mestReNova 6.0.2-5475 (Mestrelab Research, 2017).

\subsection{In vitro tests with the R. (B.) microplus ticks}

These tests were performed under SISBIO research authorization no. 37006-4. The engorged females used in this trial were obtained from cattle of the Embrapa Southeast Livestock research unit, free of acaricide treatment for at least 90 days. For the tests with larvae, 14 to 21day-old larvae from the engorged females collected from the cattle were used. The resistance of the herd's ticks is monitored annually to verify which acaricidal chemical group should be used in the animals kept by Embrapa. According to the resistance test carried out in 2016, these ticks are resistant to pyrethroids, organophosphates and amidines.

\subsubsection{Adult immersion test (AIT)}

Engorged females were harvested manually from the cattle, sanitized in tap water, dried with absorbent paper and randomly distributed in groups of 10 . The groups had a measured and balanced weight and were immerged for $5 \mathrm{~min}$. in $5 \mathrm{~mL}$ of $O$. elegans at concentrations of 100 , $50,25,12.5$ and $6.25 \mathrm{mg} / \mathrm{mL}$, in triplicates. The same procedure was performed for the control groups with distilled water (C1) and $75 \%$ ethanol (C2). Afterwards, the engorged females were dried, placed in Petri dishes and kept in an incubator $\left( \pm 27^{\circ} \mathrm{C}, \mathrm{RH}>80 \%\right.$ ) for 15 days for oviposition. After this period, the eggs were weighed and placed to adapted syringes, sealed with hydrophilic cotton and again incubated for another 15 days. Afterwards, the hatch estimation was performed by counting the samples in each syringe (Giglioti et al., 2011). The oviposition index, estimated hatch, reproductive efficiency index and oil efficacy were evaluated according to Drummond et al. (1973).

\subsubsection{Larval packet test ( $L P T)$}

Filter paper sheets $(2 \mathrm{~cm} \times 2 \mathrm{~cm})$ were impregnated with $1 \mathrm{~mL}$ of $O$. elegans oil at concentrations of 100, 50, 25, 12.5, 6.25, 3.12, 1.56 and $0.78 \mathrm{mg} / \mathrm{mL}$. About 100 larvae were deposited on each sheet impregnated with the solution. The sheets were then folded to form packets and were placed in the incubator $\left( \pm 27^{\circ} \mathrm{C}\right.$ and $\mathrm{RH}>80 \%$ ) (FAO, 1971). Readings were performed after $24 \mathrm{~h}$, counting the dead and live larvae using a vacuum pump with an adapted pipette tip. The same concentrations were also evaluated after $48 \mathrm{~h}$ of exposure. Three replicates were performed for each concentration, as well as for the control groups, which were composed of: water (C1) and distilled water $+2 \%$ tween $80(\mathrm{C} 2)$.

\subsubsection{Larval repellency test ( $R T)$}

The repellent activity was evaluated $6 \mathrm{~h}$ after immersion of wood toothpicks (25 cm long) in O. elegans at concentrations of 100, 50, 25, $12.5,6.25,3.12,1.56$ and $0.78 \mathrm{mg} / \mathrm{mL}$. The first part of the toothpick near the base $(15 \mathrm{~cm})$ had no contact with the solution, while the middle part $(15-20 \mathrm{~cm})$ and the upper end $(20-25 \mathrm{~cm})$ remained immersed in the solutions for 20 min. in Falcon tubes. The toothpicks of the control groups were immersed in distilled water (C1) and distilled water $+2 \%$ Tween 80 (C2). After immersion, each toothpick was fixed in the center of a disposable plastic cup $(50 \mathrm{~mL})$ containing plaster, with the wet end up. A quantitative filter paper (JP41, black band, $12.5 \mathrm{~cm}$ radius, $28 \mu \mathrm{m}$ pores) was cut in an octagonal form ( $\pm 3 \mathrm{~cm}$ each side) and inserted at the toothpick base. Approximately 100 larvae were added to each toothpick base (between 2 and $4 \mathrm{~cm}$ ). They moved on the toothpick or they were dispersed on filter paper. Each treatment and control was performed in triplicate. Subsequently, larvae of each area were quantified with a vacuum pump, estimating the repellency of $O$. elegans. 
Table 1

${ }^{1} \mathrm{H}$ and ${ }^{13} \mathrm{C}$ NMR data of the substance sesquirosefuran, in ppm. Analysis by means of PRESAT, COSY, APT, HSQC and HMBC.

\begin{tabular}{lll}
\hline Position & $\delta \mathrm{H}$ & $\delta \mathrm{C}$ \\
\hline 1 & $7.20(\mathrm{~d})$ & 139.00 \\
2 & $6.15(\mathrm{~d})$ & 124.33 \\
3 & - & 136.48 \\
4 & - & 150.00 \\
5 & $3.28(\mathrm{~d})$ & 39.66 \\
6 & multiplet & 120.10 \\
7 & - & 131.56 \\
8 & - & 26.72 \\
9 & - & 25.25 \\
10 & multiplet & 112.93 \\
11 & - & 113.52 \\
12 & $1.70(\mathrm{~s})$ & 17.80 \\
13 & $1.96(\mathrm{~s})$ & 25.79 \\
14 & $1.59(\mathrm{~s})$ & 9.92 \\
15 & $1.67(\mathrm{~s})$ & 16.24 \\
\hline
\end{tabular}

$\mathrm{d}=$ doublets, $\mathrm{s}=$ singlets

\subsection{Statistical analysis}

The data of the reproductive parameters, mortality, and repellency caused by the $O$. elegans essential oil on the ticks were evaluated by a completely randomized design using the PROC GLM procedure, whose model included the fixed dose effect and the averages compared by the Tukey test $(\mathrm{p}<0.05)$. The determination of the lethal concentrations (LCs) of the essential oil in AIT, LPT and RT was performed through probit linear regression, using the normal distribution and the generalized linear model for binary data (logistic regression), with estimates of the parameters of these equations by maximum likelihood. $\mathrm{LC}_{50}$ and $\mathrm{LC}_{90}$ were then estimated. The data were analyzed by the statistical SAS software (2002/2010).

\section{Results}

The $O$. elegans leaves' essential oil presented light yellow appearance and had a pleasant odor. Eleven sesquiterpene compounds were identified, with sesquirosefuran being the major constituent, corresponding to $92.2 \%$ of the total relative composition. Table 1 shows the results of the ${ }^{1} \mathrm{H}$ and ${ }^{13} \mathrm{C}$ NMR analyses of the chemical compound sesquirosefuran. The ${ }^{1} \mathrm{H}$ NMR spectrum (Fig. 1) presented four signals relating to the methyls, appearing as singlets at $\delta 1.96,1.70,1.67$ and 1.59 , a signal for the hydrogen attached to carbon 5 , which appeared as a doublet at $\delta 3.28$, a multiplet in the region proximal to $\delta 5.08$, and two doublets at $\delta 6.15$ and 7.20, referring to the hydrogens attached to carbons 2 and 1, respectively. The following signals (in $\delta \mathrm{ppm}$ ) were observed in the ${ }^{13} \mathrm{C}$ NMR spectra: 150.00 (C-4), 139.90 (C-1), 136.48 (C-3), 131.56 (C-7), 124.33 (C-2), 120.10 (C-6), 113.52 (C-11), 112.93 (C-10), 39.66 (C-5), 26.72 (C-8), 25.79 (C-13), 25.25 (C-9), 17.80 (C12), 16.24 (C-15), 9.92 (C-14). These were consistent with the data found in the SciFinder database, Chemical Abstracts Service.

In the AIT, as expected, the control groups had the highest mean egg weight, in function of the higher oviposition by the females. O. elegans oil at concentrations of 25,50 and $100 \mathrm{mg} / \mathrm{mL}$ resulted in the lowest mean egg weights $(0.32,0.06$ and $0.03 \mathrm{~g}$, respectively), larval hatching ( $8 \%, 0 \%$ and $0 \%$, respectively), and reproductive efficiency index (2.63\%, $0 \%$ and $0 \%$, respectively), achieving the highest efficacies ( $97.18 \%, 100 \%$ and $100 \%$, respectively). From the concentration of $12.5 \mathrm{mg} / \mathrm{mL}$ down, the efficacy was lower, but remained higher than $60 \%$ (Table 2).

The effect of the $O$. elegans essential oil on $R$. (B.) microplus larvae can be seen in Table 3 , in which the mortality rates obtained in the LPT and the repellency percentages obtained in the RT are shown. In general, LPT1 $(24 \mathrm{~h})$ caused low mortality rates, presenting some efficacy from the $12.5 \mathrm{mg} / \mathrm{mL}$ concentration up. So, no significant differences between treatments and controls were observed. In LPT2 (48 h), larval mortality started at $3.12 \mathrm{mg} / \mathrm{mL}$, with emphasis on the $100 \mathrm{mg} / \mathrm{mL}$ concentration, in which $77.40 \%$ mortality was detected, resulting in a statistical difference from the others. LPT3 $(48 \mathrm{~h})$ was performed to confirm the results obtained in LPT2. The results followed a similar pattern to LPT2, with larval mortality starting at $3.12 \mathrm{mg} / \mathrm{mL}$ concentration, with no difference $(\mathrm{p}>0.05$ ) between concentrations, except for $100 \mathrm{mg} / \mathrm{mL}$.

Regarding RT, high percentage of larval repellency was obtained at the lowest concentration $(0.78 \mathrm{mg} / \mathrm{mL})$. At $1.56 \mathrm{mg} / \mathrm{mL}$, despite having lower mean repellency than $0.78 \mathrm{mg} / \mathrm{mL}(85.23 \%$ and $91.19 \%$, respectively), the numbers did not differ statistically from 0.78 and $6.25 \mathrm{mg} / \mathrm{mL}$ concentrations. Repellency of $100 \%$ was verified at $50 \mathrm{mg}$ / $\mathrm{mL}$ and $100 \mathrm{mg} / \mathrm{mL}$ (Table 3 ).

From the results obtained in each test, it was possible to estimate the lethal concentrations of $O$. elegans essential oil on $R$. (B.) microplus. The $\mathrm{LC}_{50}$ in the two LPTs $(48 \mathrm{~h})$ were 59.68 (41.34-100.51) and 25.59 (14.23-58.57) $\mathrm{mg} / \mathrm{mL}$, respectively. The $\mathrm{LC}_{50}$ and $\mathrm{LC}_{90}$ in the AIT were $4.96(2.02-7.22)$ and $17.37(12.52-33.23) \mathrm{mg} / \mathrm{mL}$, and in the RT they were $0.04(0.01-0.15)$ and $1.24(0.49-2.14) \mathrm{mg} / \mathrm{mL}$, respectively. These data revealed that in both AIT and RT bioassays, good performance of $O$. elegans was detected, confirming its acaricidal and repellent actions.

\section{Discussion}

The present study confirmed the presence of sesquiterpenes in the essential oil of $O$. elegans leaves. In previous chemical studies, those substances had been indicated as predominant in the genus Ocotea. They have been cited as responsible for the biological activities against insects, ticks and other organisms (Camargo et al., 2013; Moraes, 2012; Nogueira et al., 2014a,b). The ${ }^{13} \mathrm{C}$ and ${ }^{1} \mathrm{H}$ NMR analysis of sesquirosefuran revealed correspondence of the results with the literature data (Masahiro et al., 1982). The substance was identified and appears in the Scifinder library under CAS number 39007-93-7 and its signal spectrum had similar results to those described by Tada et al. (1982). Sesquirosefuran has also been detected in other species of the Lauraceae family, such as Lindera strychnifolia (Siebold \& Zucc.) Fern.-Vill., Neolitsea aciculate (Blume) Koidz., Neolitsea sericea (Blume) Koidz,. Neolitsea zeylanica (Nees \& T. Nees) Merr. (Gottlieb, 1972), and Actinodaphne longifolia (Blume) Nakai (Hayashi and Komae, 1980). Various interesting properties have been demonstrated for sesquirosefuran. We can highlight its termiticidal properties (Ozaki, 1999) and potential as a biogenetic precursor of substances with important pharmacological properties, such as the formation of litseaverticillols (sesquiterpenes isolated from a Vietnamese shrub), which have anti-HIV activity (Margaros et al., 2006). In chemical studies, involving auto-oxidation by biomimicry in chemical synthesis, the sesquirosefurans perylene, rosefuran and litseaverticillols presented intermediate potential for synthesis (Margaros et al., 2006; Tada et al., 1982).

This is the first study involving the biological effect of $O$. elegans essential oil on $R$. (B.) microplus ticks. At concentrations of 50 and $100 \mathrm{mg} / \mathrm{mL}$ it interfered in oviposition in the AIT as well as hatching, resulting in $100 \%$ efficacy. Moreover, $63.9 \%$ efficacy at $6.2 \mathrm{mg} / \mathrm{mL}$ concentration was observed. These results indicate reduction of the reproductive function of engorged females. Therefore, we believe it should be better studied at the histological level. Our results are close to those of Barbosa et al. (2013), in which ethanol extract of O. lancifolia (Schott) Mez leaves and bark at $2 \mathrm{mg} / \mathrm{mL}$ showed significant activity on the reproductive parameters of $R$. (B.) microplus engorged females (34.5\% efficacy). Conceição et al. (2017) also obtained efficacy higher than $90 \%$ with the ethanol extract of $O$. aciphylla (Nees \& Mart.) Mez leaves at $50 \mathrm{mg} / \mathrm{mL}$ in the AIT against $R$. (B.) microplus. The last authors also verified larvicidal activity of $O$. aciphylla and stated that the larval stage was more susceptible than the adult stage, suggesting this may be 


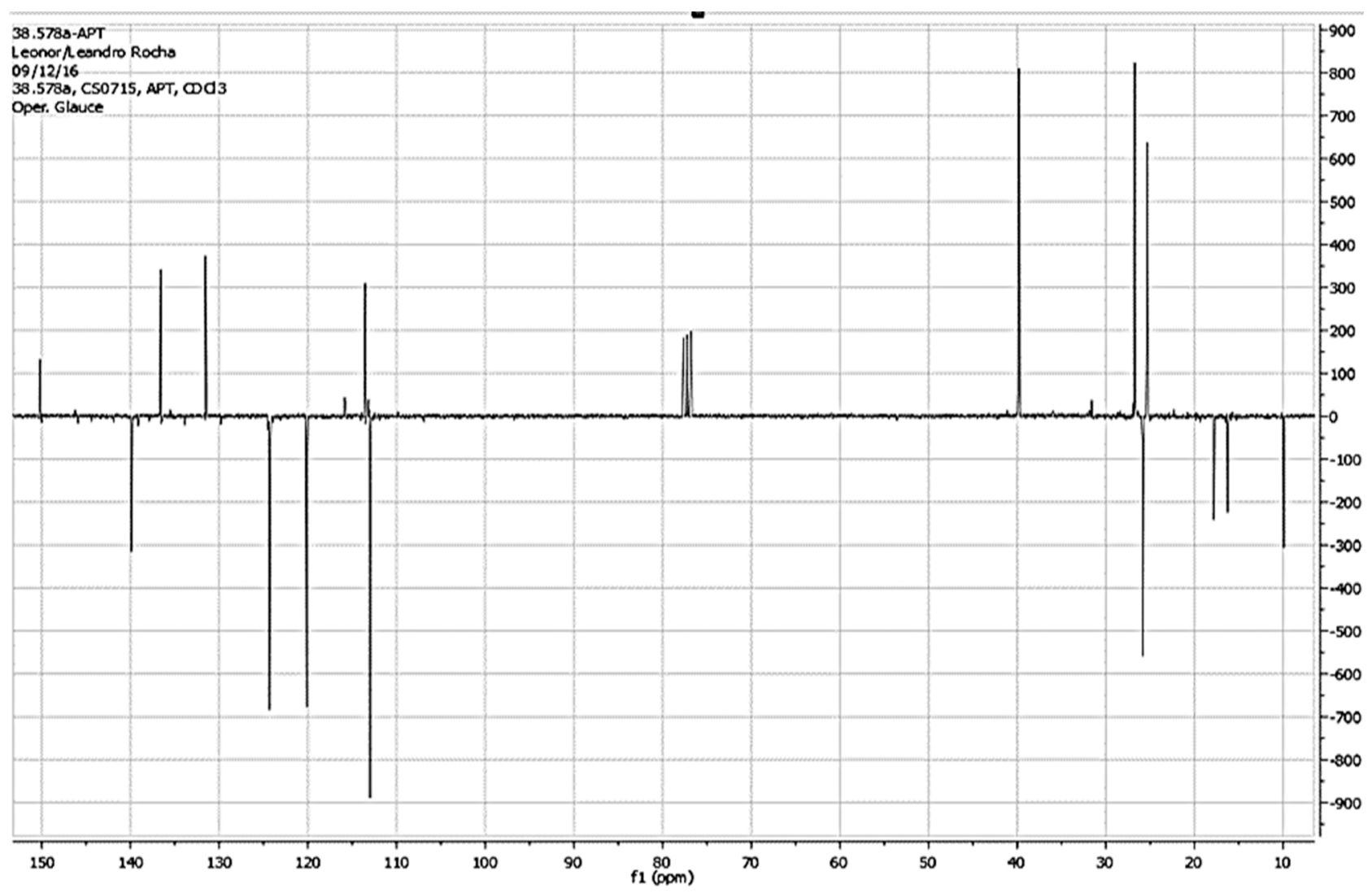

Fig. 1. NMR spectra of sesquirosefuran and its respective ${ }^{13} \mathrm{C}$ carbon chemical shifts $(100 \mathrm{MHz}, \mathrm{CDCl} 3)$.

related to the difference in cuticle composition, which is thinner in larvae (Silva et al., 2009).

In the present study, larval susceptibility was also observed, especially in RT, in which $12.5 \mathrm{mg} / \mathrm{mL}$ repelled $99 \%$ of the larvae after $6 \mathrm{~h}$. It was also possible to observe high repellency rates at the lowest concentrations. These results are similar to those of Zeringóta et al. (2013), in which eugenol was evaluated (substance present in many species of the Lauraceae family). Repellent rates higher than $90 \%$ in the first $7 \mathrm{~h}$ were observed for tick larvae at 30,40 and $50 \mathrm{mg} / \mathrm{mL}$.

The present study did not demonstrate good larvicidal performance of the O. elegans essential oil in the LPTs. After $24 \mathrm{~h}$ of contact, the mortality rate was only $34.5 \%$ at $100 \mathrm{mg} / \mathrm{mL}$, and around $76 \%$ at $100 \mathrm{mg} / \mathrm{mL}$ in both $48 \mathrm{~h}$ tests. On the other hand, studies evaluating ethanol extracts of other species of the Ocotea genus have obtained better results on $R$. (B.) microplus larvae. Extracts of $O$. diospyrifolia, for example, produced mortality above $95 \%$ in the larval immersion test (LIT) at 40\% concentration (Santos et al., 2013). O. aciphylla also had efficacy higher than $90 \%$ in the LPT at $50 \mathrm{mg} / \mathrm{mL}$ (Conceição et al., 2017). These findings may be related to the type of extraction from the plant material, as well as the difference of composition among species, since this can vary widely in the same genus (Chagas, 2015). Therefore, we suggest that other forms of extraction also should be explored for $O$. elegans, to evaluate its potential against $R$. (B.) microplus.

We believe that the sesquiterpene sesquirosefuran, the major constituent of the essential oil, contributed fundamentally to the acaricidal and repellent activities of $O$. elegans against $R$. (B.) microplus in the present study. For this reason, formulations with $O$. elegans oil or with the sesquirosefuran need to be developed and evaluated to find better compounds for cattle tick control in the future. Sesquirosefuran could be incorporated in the synthetic acaricides available, adding repellent action. However, since the yield of the $O$. elegans oil extraction was very low $(0.4 \%)$, genetic selection to obtain genotypes suitable for commercial production of this species by improving oil production would be interesting. In addition, the search for a route to synthesize sesquirosefuran is also important. Once the sesquiterpene quantity question has been solved, morpho-histological studies of the tick ovaries can confirm the ability to inhibit reproduction, and subsequently formulations based on sesquirosefuran can be evaluated in toxicological and pre clinical trials.

Table 2

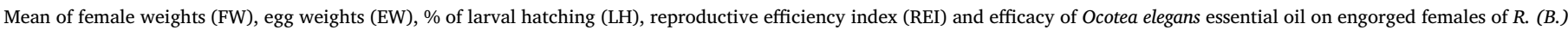
microplus, evaluated by the adult immersion test (AIT)

\begin{tabular}{|c|c|c|c|c|c|}
\hline Concentration $^{*}(\mathrm{mg} / \mathrm{mL})$ & FW (g) & EW (g) & LH (\%) & REI & Efficacy (\%) \\
\hline C1 (water) & $2.29 \pm 0.00 \mathrm{a}$ & $1.09 \pm 0.07 a$ & $98.00 \pm 0.00 \mathrm{a}$ & $93.30 \pm 6.71 \mathrm{a}$ & - \\
\hline C2 (ethanol) & $2.30 \pm 0.00 \mathrm{a}$ & $0.81 \pm 0.09 \mathrm{a}, \mathrm{b}$ & $88.33 \pm 2.88 \mathrm{a}$ & $62.19 \pm 5.26 \mathrm{a}, \mathrm{b}$ & - \\
\hline 6.2 & $2.29 \pm 0.00 \mathrm{a}$ & $0.66 \pm 0.14 b$ & $55.00 \pm 39.05 a, b$ & $33.65 \pm 25.64 \mathrm{~b}, \mathrm{c}$ & $63.93 \pm 27.48 \mathrm{a}$ \\
\hline 12.5 & $2.32 \pm 0.01 \mathrm{a}$ & $0.77 \pm 0.07 \mathrm{~b}$ & $36.00 \pm 15.27 b, c$ & $25.13 \pm 12.43 \mathrm{c}, \mathrm{d}$ & $73.07 \pm 13.32 \mathrm{a}$ \\
\hline 25 & $2.29 \pm 0.01 \mathrm{a}$ & $0.32 \pm 0.14 c$ & $8.00 \pm 10.39 c$ & $2.63 \pm 3.68 \mathrm{c}, \mathrm{d}$ & $97.18 \pm 3.95 a$ \\
\hline 50 & $2.29 \pm 0.02 \mathrm{a}$ & $0.06 \pm 0.11 c$ & $0.00 \pm 00.00 c$ & $0.00 \pm 0.00 \mathrm{~d}$ & $100.00 \pm 0.00 \mathrm{a}$ \\
\hline 100 & $2.32 \pm 0.01 \mathrm{a}$ & $0.03 \pm 0.03 c$ & $0.00 \pm 0.00 c$ & $0.00 \pm 0.00 \mathrm{~d}$ & $100.00 \pm 0.00 \mathrm{a}$ \\
\hline
\end{tabular}

* Different letters in the column indicate statistically significant difference (Tukey test, $p<0.05$ ). 
Table 3

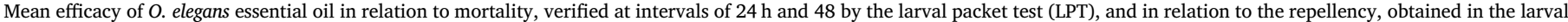
repellency test (RT).

\begin{tabular}{|c|c|c|c|c|}
\hline \multirow[t]{2}{*}{ Concentration $(\mathrm{mg} / \mathrm{mL})^{*}$} & \multicolumn{3}{|l|}{ Mortality (\%) } & \multirow{2}{*}{$\begin{array}{l}\text { Repellency (\%) } \\
\text { RT }\end{array}$} \\
\hline & LPT 1 (24 h) & LPT 2 (48 h) & LPT 3 (48 h) & \\
\hline C1 (water) & $0.00 \pm 0.00 \mathrm{a}$ & $0.00 \pm 0.00 \mathrm{~d}$ & $0.00 \pm 0.00 \mathrm{~b}$ & $19.44 \pm 6.89 c$ \\
\hline C2 (ethanol) & $0.00 \pm 0.00 \mathrm{a}$ & $0.00 \pm 0.00 \mathrm{~d}$ & $0.00 \pm 0.00 \mathrm{~b}$ & $8.07 \pm 4.00 c$ \\
\hline 0.78 & $0.00 \pm 0.00 \mathrm{a}$ & $0.00 \pm 0.00 \mathrm{~d}$ & $0.00 \pm 0.00 \mathrm{~b}$ & $91.19 \pm 7.51 \mathrm{a}, \mathrm{b}$ \\
\hline 1.56 & $0.00 \pm 0.00 \mathrm{a}$ & $0.00 \pm 0.00 \mathrm{~d}$ & $0.00 \pm 0.00 \mathrm{~b}$ & $85.23 \pm 3.35 b$ \\
\hline 3.12 & $0.00 \pm 0.00 \mathrm{a}$ & $10.99 \pm 6.37 \mathrm{c}, \mathrm{d}$ & $7.59 \pm 5.31 b$ & $97.85 \pm 2.32 \mathrm{a}$ \\
\hline 6.25 & $0.00 \pm 0.00 \mathrm{a}$ & $5.25 \pm 0.70 \mathrm{~d}$ & $37.73 \pm 54.13 a, b$ & $94.21 \pm 5.95 \mathrm{a}, \mathrm{b}$ \\
\hline 12.5 & $6.71 \pm 9.98 a$ & $22.81 \pm 4.34 \mathrm{~b}, \mathrm{c}$ & $31.12 \pm 20.15 a, b$ & $99.11 \pm 1.52 \mathrm{a}$ \\
\hline 25 & $8.25 \pm 4.42 \mathrm{a}$ & $23.90 \pm 7.94 b, c$ & $52.26 \pm 9.22 \mathrm{a}, \mathrm{b}$ & $99.11 \pm 0.86 a$ \\
\hline 50 & $10.82 \pm 17.88 \mathrm{a}$ & $28.43 \pm 8.69 b$ & $61.23 \pm 33.66 \mathrm{a}, \mathrm{b}$ & $100.00 \pm 0.00 \mathrm{a}$ \\
\hline 100 & $34.48 \pm 47.61 \mathrm{a}$ & $77.40 \pm 8.40 \mathrm{a}$ & $76.25 \pm 21.90 \mathrm{a}$ & $100.00 \pm 0.00 \mathrm{a}$ \\
\hline
\end{tabular}

* Different letters in the column indicate statistically significant difference (Tukey test, $p<0.05$ ).

\section{Conclusions}

The essential oil of the $O$. elegans leaves presents acaricidal activity, especially on engorged females' reproductive parameters, and has repellent activity against larvae, demonstrating promise for the control of $R$. (B.) microplus. Future studies should also focus on the synthesis of sesquirosefuran, for its inclusion in a formulation with commercially available acaricides, to improve their action.

\section{Statement of animal rights}

The experimental protocols that were developed in this study fully complied with the ethical principles of animal experimentation prepared by Ethical Use of Animals of Embrapa Pecuária Sudeste committee (CPPSE/ Protocol No. 02/2014).

\section{Conflict of interest}

The authors declare that they have no conflict of interest.

\section{Acknowledgments}

We thank the Conselho Nacional de Desenvolvimento Científico e Tecnológico (CNPq), for the scholarships granted, Empresa Brasileira de Pesquisa Agropecuária (Embrapa - Project 02.13.01.001.00-00) and Fundação Carlos Chagas Filho de Amparo à Pesquisa do Estado do Rio de Janeiro (FAPERJ) for financial support.

\section{References}

Adams, R.P., 2007. Identification of Essential Oils Components by Gas Chromatography/ Mass Spectrometry. Allured Publishing Corporation, Illinois.

Barbosa, C.S., Borges, L.M.F., Nicácio, J., Alves, R.D., Miguita, C.H., Violante, I.M.P., Hamerski, L., Garcez, W.S., Garcez, F.R., 2013. In vitro activities of plant extracts from the Brazilian Cerrado and Pantanal against Rhipicephalus (Boophilus) microplus (Acari: Ixodidae). Exp. Appl. Acarol. 60, 421-430.

Camargo, M.J., Miranda, M.L.D., Kagamida, C.M., Rodrigues, E.D., Garcez, F.R., Garcez, W.S., 2013. Sesquiterpeno em Ocotea lancifolia (Lauraceae). Quím. Nova 36, 1008-1013.

Chagas, A.C.S., 2015. Medicinal plant extracts and nematode control. CAB Rev. 10, 1-8. Conceição, R.S., Carneiro, M.M.A.A., Reis, I.M.A., Branco, A., Vieira, I.J.C., Braz-Filho, R., Botura, M.B., 2017. In vitro acaricide activity of Ocotea aciphylla (Nees) Mez. (Lauraceae) extracts and identification of the compounds from the active fractions. Ticks Tick Borne Dis. 8, 275-282.

Cruz, B.C., Lopes, W.D.Z., Macial, W.G., Felippelli, G., Fávero, F.C., Teixeira, W.F.P., Carvalho, R.S., Ruivo, M.A., Colli, M.H.A., Sakamoto, C.A.M., Costa, A.J., Oliveira, G.P., 2015. Susceptibility of Rhipicephalus (Boophilus) microplus to ivermectin (200, 500 and $630 \mathrm{~g} / \mathrm{kg}$ ) in field studies in Brazil. Vet. Parasitol. 207, 309-317.

Drummond, R.O., Ernest, S.E., Trevino, J.L., Gladney, W.J., Graham, O.H., 1973. Boophilus annulatus and B. microplus: laboratory tests of insecticides. J. Econ. Entomol. 66, 130-133.

FAO, 1971. Recommended method for the detection and measurement of resistance of agricultural pests to pesticides: tentative methods for larvae of cattle tick Boophilus spp. Plant Prot. Bull. 19, 15-18.

Furtado, F.N., Silva, V.A.R., Pereira, J.R.G., Kisue, A., Coêlho, F.A.S., Coêlho, M.D.G., 2013. Avaliação in vitro do potencial acaricida do óleo essencial de Tagetes minuta frente à Rhipicephalus (Boophilus) microplus (Canestrini, 1887). Rev. Biociênc. 19, $104-110$.

Giglioti, R., Forim, M.R., Oliveira, H.N., Chagas, A.C.S., Ferrezini, J., Brito, L.G., Falcoski, T.O.R.S., Albuquerque, L.G., Oliveira, M.C.S., 2011. In vitro acaricidal activity of neem (Azadirachta indica) seed extracts with known azadirachtin concentrations against Rhipicephalus microplus. Vet. Parasitol. 181, 309-315.

Gottlieb, O.R., 1972. Chemosystematics of Lauraceae. Phytochemistry 11, 1537-1570.

Grisi, L., Leite, R.C., Martins, J.R.S., Barros, A.T.M., Andreotti, R., Cançado, P.H.D., Perez de León, A.A., Pereira, J.B., Villela, H.S., 2014. Reassessment of the potential economic impact of cattle parasites in Brazil. Braz. J. Vet. Parasitol. 23, 150-156.

Hayashi, N., Komae, H., 1980. Chemistry and distribution of sesquiterpene furans in Lauraceae. Biochem. Syst. Ecol. 8, 381-383.

Hess, S.C., 1995. Estudos Químicos, Biológicos e Farmacológicos com Vochysia divergens Pohl (Vochysiaceae) e com Ocotea Suaveolens (Meissn.) Hassler (Lauraceae). Universidade Federal de Santa Catarina, Florianópolis.

Higa, L.O.S., Garcia, M.V., Barros, J.C., Koller, W.W., Andreotti, R., 2016. Evaluation of Rhipicephalus (Boophilus) microplus (Acari: Ixodidae) resistance to different acaricide formulations using samples from Brazilian properties. Rev. Bras. Parasitol. Vet. 25, 163-171.

Klafke, G., Webster, A., Dall Agnol, B., Pradel, E., Silva, J., de La Canal, L.H., Becker, M., Osório, M.F., Mansson, M., Barreto, R., Scheffer, R., Souza, U.A., Corassini, V.B., Dos Santos, J., Reck, J., Martins, J.R., 2017. Multiple resistance to acaricides in field populations of Rhipicephalus microplus from Rio Grande do Sul state, Southern Brazil. Ticks Tick Borne Dis. 8, 73-80.

Kropf, M.S., Quinet, A., Andreata, R.H.P., 2015. Lauraceae das restingas do estado do Rio de Janeiro, Brasil. Iheringia Ser. Bot. 70, 287-308.

Margaros, I., Montagnon, T., Tofi, M., Pavlakos, E., Vassilikogiannakis, G., 2006. The Power of singlet oxygen chemistry in biomimetic syntheses. Tetrahedron. 62, 5308-5317.

Marques, C.A., 2001. Importância Econômica da Família Lauraceae Lindl. Floresta e Ambiente 8, 195-206.

Marques, C.A., Barros, C.F., Costa, C.G., 2004. Beilschmiedia rigida (Mez) Kosterm. (Lauraceae): diferenciação e desenvolvimento da lâmina foliar. Rodriguesia. 55, 89-100.

Masahiro, T., Chiba, K., Hashizume, T., 1982. Formation of Dendrolasin, Sesquirosefuran, Perillene and Rosefuran by biomimetic auto oxidation. Agric. Biol. Chem. 46, 819-820.

Mello-Peixoto, E.C.T., Figueiredo, A., Novo, S.M.F., Porto, E.P., Valadares, F., Silva, L.P., Silva, R.M.G., 2013. Application of Cymbopogon winterianus Jowitt and Azadirachta indica A. Juss in the control of Rhipicephalus (Boophilus) microplus. J. Med. Plants Res. 7, 2392-2398.

Mestrelab Research S.L., 2017. Santiago de Compostela, Spain, MestreNova 6.0.1.

Moraes, M.M., 2012. Relação entre a toxicidade de mono e sesquiterpenos identificados no óleo essencial de espécies dos gêneros Ocotea (Lauraceae) e Eugenia (Myrtaceae) sobre o ácaro rajado (Tetranychus urticae). Universidade Federal Rural de Pernambuco, Recife.

Nogueira, J., Mourão, S.C., Dolabela, I.B., Santos, M.G., Brasileiro, C.B., Kelecom, A., Mexas, R., Feder, D., Fernandes, C.P., Gonzales, M.S., Rocha, L., 2014a. Zanthoxylum caribaeum (Rutaceae) essential oil: chemical investigation and biological effects on Rhodnius prolixus nymph. Parasitol. Res. 113, 4271-4279.

Nogueira, J., Vinturelle, R., Mattos, C., Tietbohl, L.A.C., Santos, M.G., Da Silva, I.V.J., Mourão, S.C., Rocha, L., Folly, E., 2014b. Acaricidal properties of the essential oil from Zanthoxylum caribaeum against Rhipicephalus microplus. J. Med. Entomol. 51, 971-975.

Ozaki, S.K., 1999. Efeitos do tratamento da Madeira com Álcool Furfurílico combinado com compostos de boro. Instituto de Física da Universidade de São Paulo, São Carlos.

Quinet, A., 2005. Sinopse taxonômica da família Lauraceae no Estado do Rio de Janeiro, Brasil. Acta Bot. Bras. 19, 563-572.

Raynal, J.T., Silva, A.A.B., Sousa, T.J., Bahiense, T.C., Meyer, R., Portela, R.W., 2013. Acaricides efficiency on Rhipicephalus (Boophilus) microplus from Bahia state North- 
Central region. Rev. Bras. Parasitol. 22, 71-77.

Rodrigues, D.C., Leite, R.C., 2013. Economic impact of Rhipicephalus (Boophilus) microplus: estimate of decreased milk production on a dairy farm. Arq. Bras. Med. Vet. Zoot. 65, 1569-1572.

Roel, A.R., 2001. Utilização de plantas com propriedades inseticidas: uma contribuição para o Desenvolvimento Rural Sustentável. Interações (Campo Grande) 1, 43-50. https://pt.scribd.com/document/124988207/01Utilizacao-de-plantas-compropriedades-inseticidasn2-railda-2001a.

Rohwer, J.G., 1993. Lauraceae. In: Kubitzki, K., Rohwer, J.G. (Eds.), Bittrich (Org.) The Families and Genera of Vascular Plants. Springer-Verlag, Berlin, pp. 366-391.

Santos, L.B., Souza, J.K., Papassoni, B., Borges, D.G.L., Damasceno Junior, G.A., Souza, J.M.E., Carollo, C.A., Borges, F.A., 2013. Efficacy of extracts from plants of the Brazilian Pantanal against Rhipicephalus (Boophilus) microplus. Rev. Bras. Parasitol. Vet. 22, 532-538.

SAS Institute, 2002/2010. SAS/INSIGHT User's Guide, versão 9.1.3, versão para Windows. Cary, NC, USA.

Silva, W.C., de Souza Martins, J.R., de Souza, H.E.M., Heinzen, H., Cesio, M.V., Mato, M., Albrecht, F., de Azevedo, J.L., de Barros, N.M., 2009. Toxicity of Piperaduncum L.
(Piperales: Piperaceae) from the Amazon forest for the cattle tick Rhipicephalus (Boophilus) microplus (Acari: Ixodidae). Vet. Parasitol. 164, 267-274.

Tada, M., Kazuhiro, C., Takeshi, H., 1982. Formation of Dendrolasin, Sesquirosefuran, Perillene and Rosefuran by biomimetic auto oxidation. Agric. Biol. Chem. 46, 819-820.

Tietbohl, L.A.C., Barbosa, T., Fernandes, C.P., Santos, M.G., Machado, F.P., Santos, K.T., Mello, C.B., Araújo, H.P., Gonzalez, M.S., Feder, D., Rocha, L., 2014. Laboratory evaluation of the effects of essential oil of Myrciaria floribunda leaves on the development of Dysdercus peruvianus and Oncopeltus fasciatus. Braz. J. Pharmacog. 24, 316-321.

Yamaguchi, K.K.L., Alcântara, J.M., Veiga Junior, V.F., 2012. Investigação do potencial antioxidante e anticolinesterásico de 20 espécies da família Lauraceae. Acta Amaz. $42,541-546$.

Zeringóta, V., Senra, T.O.S., Calmon, F., Maturano, R., Faza, A.P., Catunda-Junior, F.E.A., Monteiro, C.M.O., Carvalho, M.G., Daemon, E., 2013. Repellent activity of eugenol on larvae of Rhipicephalus microplus and Dermacentor nitens (Acari: Ixodidae). Parasitol. Res. 112, 2675-2679. 